\title{
GROWTH, UNEMPLOYMENT AND NONEXISTENCE OF LABOR MARKET IN A RAMSEY TYPE MODEL
}

\author{
Fernando A. Noriega Ureña* \\ Departamento de Producción Económica, UAM-Xochimilco \\ Ramón Tirado Jiménez \\ Departamento de Producción Económica, UAM-Xochimilco
}

(Received 15 October 2002, accepted 10 January 2003)

\begin{abstract}
This paper shows that, on the basis of a Ramsey model, a firm that maximizes the profit rate, subject to a technology with diminishing marginal products, achieves better equilibrium levels than a firm maximizing net profit. It is also shown the nonexistence of labor market and unemployment under steady state conditions.
\end{abstract}

\section{Resumen}

Este trabajo muestra, con base en un modelo del tipo de Ramsey, que una empresa competitiva que maximiza la tasa de beneficios, sujeta a una tecnología con productos marginales decrecientes, alcanza niveles de equilibrio comparativamente superiores a los que alcanzaría una empresa maximizadora del beneficio neto. Además, se demuestra que en las condiciones del estado estacionario, el mercado de trabajo y el desempleo son inexistentes.

JEL classification: J23, J64, O41

Keywords: Employment determination, Labor demand, Growth models

* Profesor Titular C, Departamento de Producción Económica, DCSH, UAM-Xochimilco. Calzada del Hueso 1100, Col. Villa Quietud, Deleg. Coyoacán, C.P. 04960, México, D.F., Telephone: 54837100, E-mail: fnoriega@cueyatl.uam.mx

Authors are grateful to the anonymous referees for their comments, and wish to thank Daniel Velázquez for valuable suggestions. 


\section{Introduction}

The aim of this paper is to describe and analyze a Ramsey type model in which a competitive firm maximizes the profit rate, instead of maximizing profits as in the neoclassical set up. Profit rate is defined by the ratio between total earnings and total production costs, minus one.

Neoclassical theory of production establishes as a main hypothesis, that firms maximize profits subject to their technology. Profits are defined as the difference between total earnings and production costs, and their maximization is subject to diminishing marginal returns in order to assure positive profits. Besides, it holds that under a competitive environment, where all economic agents take prices of goods and inputs as given, the system as a whole, i.e. the set of all individual producers and consumers, reaches an efficient solution. However, this paper shows that the profit maximization problem under competitive conditions is not an efficient solution.

In other words, it is shown that an efficient solution to the problem of the firm is based on the maximization of the rate of profit instead of the corresponding and traditional profits flow function. ${ }^{1}$ This conclusion is maintained by supposing the existence of competitive markets, decreasing returns to scale in the production side, and one composed good. That means, as it has been stated in Noriega (2001, chapter 6), that the traditional profit maximization hypothesis describes an economic agent whose behavior is inefficient, and therefore it does not support the assumption in which everyone look for maximizing their own profit. Then, in an economy where each firm maximizes the profit rate, we obtain a superior equilibrium in the sense of Pareto to that regrading an economy where firms are profit level maximizers. ${ }^{2}$

The problem analyzed in this paper does not represent a criticism to the firm theory as many authors have attempted to make. Between these authors, there are some who do not accept the framework of profit maximization as a suitable criterium to describe a reasonable firm behavior (Kreps, 1987 and 1990). Essentially, Kreps argues that the managers not always have the incentives to maximize profits in the name of shareholders, and that firms could maximize other objective functions more preferred for them. In this paper, we follow approaches that neglect the existence of firms as maximizing entities. ${ }^{3}$

Although we accept that a firm follows a rational behavior that implies maximization, and that it looks for reaching the maximum profits flow, we shall find that the maximization of profit flows is not enough to hold an efficient solution. Then, efficient solution, accepting that firms follow a maximizing behavior, rests in the maximization of profit rates.

Results shown in Noriega $(1994,2001)$ are static. This paper extends such a concept to a dynamic framework by means of a Ramsey-Cass-Koopmans type model. We begin with the explanation of a non-monetary economy with two

1 It can be seen in Noriega (1994) and (2001).

2 The referred mathematical demonstration has been published under the name of superiority theorem.

3 This same idea can be seen in Nelson and Winter (1982), and among the literature based in an evolutionary theory of production and technical change. 
types of agent: consumers and producers. We suppose the existence of a single representative consumer with infinite life, an intertemporal utility function in a competitive environment, and that derives utility from the consumption of a single good. Such a consumer maximizes a present value utility function subject to an intertemporal budget constraint. Finally, we suppose that producers maximize the profit rate on a daily basis, taking into account a technology with diminishing marginal products, since it is assumed that the firm hires capital and labor services, and has not adjustment costs. Hence, there are not intertemporal elements in firm's maximization problem.

The paper is organized as follows. In the first part, we expose a model of a decentralized economy under static conditions, in order to show the axiomatic foundations of equilibrium where firms (producers) maximize the profit rate under competitive conditions. In the second part, we state the dynamic model with profit rate maximization under regular competitive conditions. Here we derivate the steady state equilibrium and carry out stability proof, as well as unemployment existence and welfare properties introducing a central planner. Finally, in the third part, we draw some conclusions about main results of the model.

\section{Foundations of a Model with Firms Maximizing the Profit Rate}

In order to, properly, show the analytical bases of the Ramsey type model where the firm's problem is to maximize its profit rate, it is necessary to state the fundamental differences between the formal expression of the traditional hypothesis about firm's economic behavior and its equilibrium, compared to that reached by profit rate maximizing agents. For it, suppose a competitive economy with two representative agents: a consumer, who maximizes an strictly concave utility function subject to a budget restriction, and a producer, who maximizes the rate of profit, subject to a technical constraint, namely, diminishing marginal products.

Since the traditional production function with decreasing returns does not allow the maximization of profit rate, except where profit rate becomes infinite, and production and factor quantities are both zero, to make that the firm maximizes the profit rate over the efficiency frontier of the production function with non-zero production and employment, another element must be included: the distinction between the labor needed to organize the firm and the labor employed directly on production. The main implication of it, is the change in the concept of firm itself. Traditionally, firms are thought as agents pursuing profit goals just to the point where the engineering of production allows it, and the organization is completely left away of the definition. Here, we will take into account firms engineering as well as its organization.

Let us denote labor by $L$, product by $Q$, profit by $\Pi$, profit rate by $\pi$, wages by $W$, and product price by $P$. The subindex $d$ and $s$ will indicate demand or supply, respectively. Variable $L^{*}$ will correspond to the quantity of labor employed by the firm in order to organize all of its processes. In other words, $L^{*}$ will be the bigger number of contracts established by the firm in order to employ labor and to sell product, which will depend of the size of product market. It must be stated now that $L^{*}$ will not introduce neither increasing returns effects nor indivisibilities. Moreover, taking into account the traditional 
hypothesis, $L^{*}$ would not imply any change in the first order conditions for the firm. Thus, the economic calculations of representative agents are given by the following maximization problems:

\subsection{Firms}

As mentioned before, usual neoclassical representations of firms are based on the maximization of profit function,

$$
\begin{gathered}
\text { Maximize } \Pi=P Q_{s}-W L_{d}, \\
\text { s.t. } Q_{s}=f\left(L_{d}-L^{*}\right), f^{\prime}>0, f^{\prime \prime}<0,
\end{gathered}
$$

where $L_{d}>L^{*} \cdot{ }^{4}$ Moreover, note that this kind of production function does not modify the first order conditions

$$
\begin{gathered}
f^{\prime}=\frac{W}{P}, \\
Q_{s}=f\left(L_{d}-L^{*}\right) .
\end{gathered}
$$

With these two equations is possible to solve for employment and production optimum levels for the firm, once the real wage is known. Now, let us define profits level $(\Pi)$ as the result of a profit rate $(\pi)$ applied to the total costs to produce $Q$ (in this case, total wages)

$$
\Pi=\pi\left(W L_{d}\right),
$$

and replacing it in (1), the objective function becomes the profit rate instead of its level. Then, the maximizing behavior of this agent will be given by

$$
\begin{gathered}
\text { Maximize }(1+\pi)=\frac{P Q_{s}}{W L_{d}}, \\
\text { s.t. } Q_{s}=f\left(L_{d}-L^{*}\right), f^{\prime}>0, f^{\prime \prime}<0,
\end{gathered}
$$

for any $L_{d}>L^{*}$. Solving the maximization problem, we obtain the following equilibrium conditions,

$$
\begin{gathered}
\frac{\mathrm{d} f\left(L_{d}-L^{*}\right)}{\mathrm{d} L_{d}}=\frac{f\left(L_{d}-L^{*}\right)}{L_{d}}, \\
Q_{s}=f\left(L_{d}-L^{*}\right), \quad \forall L_{d}>L^{*} .
\end{gathered}
$$

Thus, the representative producer's equilibrium plan to maximize $\pi$, is found at the point of the production function where marginal product equals average product. Dividing both sides of (8) by the average product, it can be shown

\footnotetext{
4 The case where the production funcion is equal to $Q_{s}=f\left(L_{d}-L^{*}\right)=\sqrt{L_{d}-L^{*}}$, is widely discussed in Noriega (1998).
} 
that the equilibrium corresponds to the point of the production function where labor elasticity of product is equal to one,

$$
\frac{\mathrm{d} f\left(L_{d}-L^{*}\right)}{\mathrm{d} L_{d}} \frac{L_{d}}{f\left(L_{d}-L^{*}\right)}=1
$$

Given the real wage, the slope of the isorate of profit function will depend exclusively on $\pi$. The following figure shows the firm's equilibrium,

Figure 1. Firm's Equilibrium.

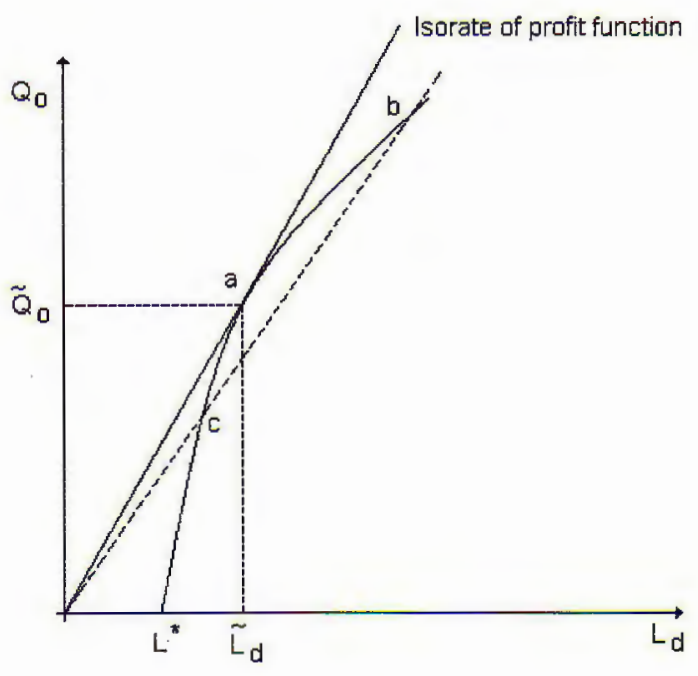

Point " $a$ " shows the agent's equilibrium. Another point of the production function, for instance " $\mathrm{b}$ " or " $\mathrm{c}$ ", the profit rate will be lower. Considering that a neoclassical equilibrium would correspond to any point to the right of "a", like " $\mathrm{b}$ ", there is evidence that maximizing $\Pi$ will necessarily lead to an inferior profit rate, regarding maximum $\pi$, which is referred in "a". Maximum $\pi$ will always match the maximum average product.

In order to calculate employment and production equilibrium levels, it is needed to solve the system given by the first order conditions (8) and (9). To see this, suppose that function (7) is homogeneous of degree $\mu, \mu>0$, in $\left(L_{d}-L^{*}\right)$. Then, in virtue of Euler's theorem, (9) can be written as follows,

$$
\mu Q_{s}=\frac{\mathrm{d} f\left(L_{d}-L^{*}\right)}{\mathrm{d} L_{d}}\left(L_{d}-L^{*}\right) .
$$

Replacing (10) into $\left(8^{\prime}\right)$ and solving for $L_{d}$, we get the following labor demand function,

$$
L_{d}=(1-\mu)^{-1} L^{*} \text {. }
$$

Now, substituting (11) in (9), we get the corresponding product supply function,

$$
Q_{s}=f\left(\mu(1-\mu)^{-1} L^{*}\right) .
$$


Since (9) is homogeneous of degree $\mu$ and defines the set of all possible firm's equilibria for all $L^{*} \geq 0$, its graphic will be,

Figure 2. Product Supply Funtion.

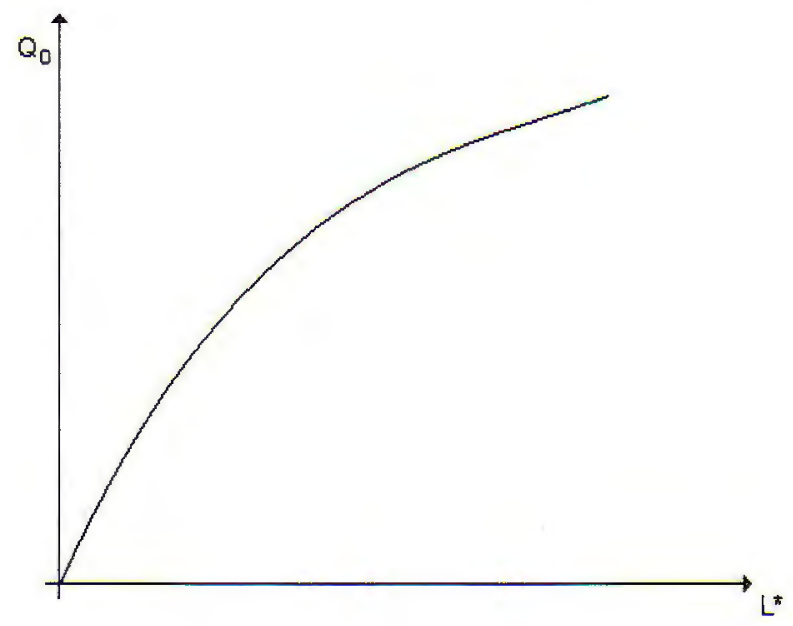

Both functions (11 and 12) show some fundamental results. On the one hand, we have that labor demand is independent of $W$ and $P$, and exclusively dependent on the size of market through $L^{*}$. Independently of the characteristics that labor supply could have, the labor market will not be performed, unlike the neoclassical framework takes place. This market does not exist in the competitive structure of our model. Firms will not employ higher levels of labor if wages decrease like the neoclassical theory predicts commonly. They will only increase employment if $L^{*}$ rises, and it will only happen if the number of contracts grows. Since firms do not follow the signal of wages to take their decisions, they will decide the employment level that maximizes their profit rate according to the number of contracts they are supposed to accomplish. It means that labor demand will increase (decrease) if market expands (reduces) its size. The inverse relation between wages and employment, fundamental in the traditional hypothesis frame, does not exist here.

On the other hand, we have the product supply function, which is independent of $W$ and $P$ as well. This one becomes positive regarding $L^{*}$ (like the labor demand), even though its slope decreases as long as $L^{*}$ grows. That is, the rational behavior of firm is related with the size of sales, once the prices and wages assure economic viability of production.

Labor demand and product supply functions imply that firms will maximize their profit rate iff $W$ and $P$ ensure profits for the firm. Given $W$ and $P$, if firms sell less than what market demands, they would be missing possible profits, as well as if they produce more than what market requires. Then, the firms will always follow market demand as the signal to maximize. 
Finally, it is important to point out that it can be shown that in equations (6) to (12) there is more than one pair $(W, P)$ that would fit each one $\left(L_{d}, Q_{s}\right)$ couple. The usual one-to-one relation between prices and quantities has been abandoned by results.

\subsection{Consumer}

Our representative agent maximizes a strictly concave utility function defined on two independent variables: leisure, $S$, and consumption, $Q_{d}$. Leisure is defined as the difference between labor, $L_{s}$, and total available time, $\tau$. Then,

$$
S=\left(\tau-L_{s}\right)
$$

Hence, the maximizing behavior of the consumer will be given by

$$
\begin{aligned}
& \text { Maximize } U=u\left(Q_{d}, S\right), \\
& \text { s.t. }(1+\pi) W L_{s}=P Q_{d} .
\end{aligned}
$$

The first order conditions are given by

$$
\begin{gathered}
-\left(\frac{\partial u}{\partial L_{s}} / \frac{\partial u}{\partial Q_{d}}\right)=(1+\pi) \frac{W}{P} \\
(1+\pi) W L_{s}=P Q_{d} .
\end{gathered}
$$

The budget constraint corresponds to a regime of property where each consumer only owns its right and capacity to work. The property rights on firms will be distributed among the consumers by the economy, through the work contracts. These rights are not previously assigned, as the traditional hypothesis usually states. So representative consumer will receive a part of his income from its labor supply (wages), and another part from its property rights on firms, represented in (17) by the term $\pi W L_{s}$. If an agent is not employed at all, its income will be zero.

It is possible to verify that the income-expenses ratio of the firm, derived from (6), along with the budget constraint of consumer, equation (15), lead to the Walras' law expression that assures the accountable consistency of the model,

$$
P\left(Q_{d}-Q_{s}\right)+(1+\pi) W\left(L_{d}-L_{s}\right)=0 .
$$

By definition, we can write the marginal rate of substitution at the equilibrium point, as a fixed proportion

$$
\frac{\phi Q_{d}}{\left(\tau-L_{s}\right)}=(1+\pi) \frac{W}{P}
$$

The parameter $\phi$ is a real positive number which comes from the parametric structure of preferences. Replacing $\left(16^{\circ}\right)$ in (16) and solving the system, we get the following results, 
i) Product demand function (or consumption function)

$$
Q_{d}=(1+\phi)^{-1}\left[\frac{(1+\pi) W \tau}{P}\right]
$$

ii) Labor supply function

$$
L_{s}=(1+\phi)^{-1} \tau \text {. }
$$

We can see that both functions have a standard shape. Product demand function is directly related to income and inversely to $P$. Labor supply is inelastic to wages, due to the flexibility of the mechanism of property rights assignment that we have assumed. Even though we have already reached the result of nonexistence of labor market, and (20) reinforces this result, inelastic labor supply should not represent by itself any problem for labor market's performance, since it is frequently employed in neoclassical framework as a standard assumption to analyze employment and wages. However, if we associate it with labor demand (11), the result is clearly the nonexistence of something like a "labor market". Doubtless, there is a labor sector where employment phenomena is suitable for analysis, but it can not be considered a market. Thus $W / P$ is not defined neither by labor supply nor by demand, as usually stated. It becomes now a distributive variable determined exogenously to the market system, by me ans of wage bargain.

\subsection{General Equilibrium}

General equilibrium conditions for the model will be

i) Product market (the only one existing)

$$
\left(Q_{\bar{\alpha}}-Q_{s}\right)=0 .
$$

ii) Labor sector

$$
\left(L_{d}-L_{s}\right) \leq 0 .
$$

On the one hand, the excess demand function (21) is equal to zero since we assumed that $P$ and $W$ are strictly positive. On the other hand, (22) is defined with an inequality to consider the existence of unemployment. Using the following equations, we will show that unemployment exists although $P$ and $W$ are positive, and still if they change under perfect price flexibility conditions.

To see this, we substitute (12), and (19) into the equation (21), and replace (11) and (20) into (22). Thus, we get the following functions,

$$
(1+\phi)^{-1}\left[\frac{(1+\pi) W \tau}{P}\right]-f\left(\mu(1-\mu)^{-1} L^{*}\right)=0,
$$

and

$$
(1-\mu)^{-1} L^{*}-(1+\phi)^{-1} \tau \leq 0 .
$$

Now, we can solve for $L^{*}$ and obtain the equilibrium average product given by the term $(1+\pi)(W / P)$. Since we are supossing a non-monetary economy, the real wage will be a variable exogenously determined, which does not mean that 
it will be fixed. Its determination could be subject to any mechanism of price adjustment, including Walrasian criteria.

Equalizing to zero (24), it will give us the magnitude of $L^{*}$ for full employment,

$$
L^{*}=\frac{(1-\mu)}{(1+\phi)} \tau .
$$

Substituting (25) into (23), and solving it for full employment average product, we have

$$
(1+\pi)\left(\frac{W}{P}\right)=f\left(\mu \frac{\tau}{1+\phi}\right)\left(\frac{1+\phi}{\tau}\right) .
$$

This equation will stand for any positive magnitude of $L^{*}$. It means that $L^{*}$ could even be inferior to its magnitude of full employment and still determine an equilibrium solution for product market.

Let $\varepsilon$ be, $0>\varepsilon>1$, it is possible to define, using (25), an $L^{*}$ lower to its full employment magnitude

$$
\tilde{\tilde{L}}^{*}=\frac{(1-\mu)}{(1+\phi)} \tau \epsilon .
$$

Replacing (27) in (23), we get the following expression,

$$
(1+\tilde{\pi})\left(\frac{W}{P}\right)=f\left(\mu \frac{\tau \varepsilon}{1+\phi}\right)\left(\frac{1+\phi}{\tau}\right) .
$$

Now, we can see that the magnitude of the average product is lower. However, the existence of unemployment does not modify the equilibrium in the product market. Equilibrium becomes perfectly compatible with this fact, due to labor market inexistence. Real wage could change or not, but profit rate will necessarily change as the average product increases with unemployment.

Up to this point, we shall raise a question: we have to ask us the following: What are the causal relations to explain production and employment levels? The answer is that product demand determines employment level. Using equation (23)

$$
\mu(1-\mu)^{-1} L^{*}=f^{-1}\left((1+\phi)^{-1} \frac{(1+\pi) W \tau}{P}\right) .
$$

Here, labor demand, and the employment level, become positive functions of product demand. From the previous result, the size of market is defined to

$$
L^{*}=f^{-1}\left((1+\phi)^{-1} \frac{(1+\pi) W \tau}{P}\right)\left(\frac{1-\mu}{\mu}\right) .
$$

Since $W / P$ is determined exogenously, the employment, production and distribution are simultaneously settled. We can already generalize the following conclusion: market equilibrium is perpetual, independently of employment level. ${ }^{5}$

5 In this case, market will concern exclisively to the only product produced by the economy. But, it is easy to show that with more than one product, the system will admit as many markets as products exist. However, labor sector will not be one of these markets. 
For all price levels, there is a number of profitable transactions that are completely accomplished by agents in all markets, independently of whether there is unemployment or not. Firms sell exactly what market demands, if they sell more or less than it was demanded, they may loose. Hence, equilibrium in markets is, for all sides, naturally perpetual, as the model has shown it.

\section{Economic Dynamics with Profit Rate Maximization}

Let us now define a dynamic continuous time system where consumption and capital accumulation are explained from existing relationships between consumers and producers in an infinite horizon optimizing model. Here, following usual assumptions, let $N(t)$ be the total population at time $t$, with a constant growth rate given by $n$. There is only one product which can be either consumed or stored over time, depending on the intertemporal agent's decisions over resources optimal allocation. Finally, we will assume that product is considered as net rather than gross output, in order to eliminate some specific capital depreciation rules.

\subsection{Firms}

Firms maximize an instantaneous profit rate function subject to a production function with decreasing returns to scale, and specified on labor and capital.

$$
\begin{gathered}
\text { Maximize }(1+\pi(t))=\frac{Q(t)}{w(t) L(t)+r(t) K(t)}, \\
\text { s.t. } \quad Q(t)=\left(L(t)-L^{*}(t)\right)^{\alpha} K(t)^{\beta}, \\
\quad \alpha, \beta \in \mathbb{R}^{+}, \quad 0<\alpha+\beta<1 .
\end{gathered}
$$

Leaving away $t$ to simplify all expressions, and assuming that real wage is given by $w$ and interest rate by $r$, we obtain the following equations using the first order conditions.

$$
\alpha \frac{r}{w} K=(1-\alpha) L-L^{*}
$$

and

$$
\alpha \frac{L}{L-L^{*}}+\beta=1
$$

From this pair of equations, we can see that labor market will not exist in the model. On the one hand, since labor demand is independent of wages and prices in every $t$, which is a result of the producers maximization, and the other hand, the labor supply is inelastic and is exogenously determined for consumers. Nevertheless, on the bases of (34) it will shown later that aggregate employment level depends directly on wages, reverting in this way the traditional relationship between wages and employment supported by neoclassical framework. According to this framework, we know that wage should be equal to marginal productivity of labor, and that employment is inversely related to wages. 
From the first order conditions, wages cannot be determined endogenously for the model. Thus, they must be determined exogenously. This means that there is no reason to accept that wages and productivity of labor follow a regular rule, and therefore to be consistent with the concept of full employment and economic efficiency. However, nonexistence of labor market does not imply that product market does not work (neither that wages have to be sticky), since it is possible to use some adjustment rule (even a walrasian one) to determine $w$. Now, by substituting (34) into (33), we arrive to the next expression, independent of $L^{*}$, concerning the interest rate,

$$
r=\left(\frac{\beta}{1-\beta}\right) \frac{w}{k}
$$

being $k=K / L$.

\subsection{Consumers}

We assume that consumers maximize their flow of utility along time. The objective function of consumers is

$$
U(0)=\int_{0}^{\infty} u(c(t)) e^{-(\rho-n) t} \mathrm{~d} t
$$

with

$$
u(c(t))=\frac{c^{1-\theta}-1}{1-\theta} .
$$

Assuming $\rho>n$, where $\rho$ is the rate of time preference and $n$ is the rate of growth of population, we avoid that preferences are explosive. As we can see from the functional form of $u(c(t))$, the utility function is concave and continuous.

We analyze the case of a decentralized economy, thereby we postulate the following individual's budget constraint,

$$
\dot{k}=(1+\pi)(w+r(t) k(t))-c(t)-n k(t) .
$$

In equation (38), $\pi$ describes the profit rate; $w$ is the individual wage assuming that every individual supplies inelastically just a unit of labor per unit of time; $k$ is the stock of physical capital owned by each consumer assuming that all assets are equal to physical capital invested by firms; and $\dot{k}=\mathrm{d} k / \mathrm{d} t$.

The consumer problem is to maximize the objective function (36), subject to budget constraint (38). Therefore, the corresponding Hamiltonian is

$$
J=u(c(t)) e^{-(\rho-n) t}+\lambda((1+\pi)(w+r(t) k(t))-c(t)-n k(t)) .
$$

Here, $c$ is the control variable, $k$ is a state variable, and finally $\lambda$ is the co-state variable. Abstracting from the temporal notation $t$, the first order conditions are

$$
\frac{\partial J}{\partial c}=u^{\prime}(c) e^{-(\rho-n) t}-\lambda=0,
$$




$$
\dot{\lambda}=-\lambda((1+\pi) r-n) .
$$

Differentiating (40) with respect to time, replacing the result in the left hand side of (41), then consider the fact that $\lambda=u^{\prime}(c) e^{-(\rho-n) t}$ in (41), and the functional form (37), we obtain that

$$
r=\frac{\theta \dot{c} / c+\rho}{(1+\pi)}
$$

In equilibrium, we have, from (42), that the interest rate equals the inverse of the elasticity of substitution times the rate of growth of consumption plus the rate of time preference, as a proportion of the rate of profit factor. The main difference of this result, compared with the traditional, is that in equilibrium, the rate of interest is inversely related to the rate of profit. In the usual approach, the rate of profit does not appear in the analysis since the objective funcion of producers is the flow of profits, instead of the rate of profit.

The intuition behind this later equation can be expressed as follows: If the return on investment, i.e. the rate of profit, increases, it will imply that the cost of a unit of capital will tend to decrease, since the investment becomes attractive for entrepreneurs while the market expands.

From (42), we arrive to the growth rate for consumption,

$$
\frac{\dot{c}}{c}=\frac{(1+\pi) r-\rho}{\theta} \text {. }
$$

Expression (43) is the Euler's equation. ${ }^{6}$ The growth rate of consumption is an increasing function of profit and interest rate. If we assume that the rate of profit is the total return over the resources invested, capital and labor, in this model, we have that the representative consumer is interested on increasing future consumption as profit rate becomes greater. In the same way, the grater is the return on capital stock $r$, the bigger the stimulus agents will have to increase future consumption. Finally, and as anyother Ramsey type model, the growth rate of consumption decreases as greater are the rate of time preference and the elasticity of substitution.

\subsection{Equilibrium}

From the above analysis, we have the next motion equations:

$$
\begin{gathered}
\dot{k}=(1+\pi)(w+r k)-c-n k, \\
\frac{\dot{c}}{c}=\frac{(1+\pi) r-\rho}{\theta} .
\end{gathered}
$$

6 The usual Euler's equation in a model with intertemporal features following the classical form of a Ramsey-Cass-Koopmans model in a non-monetary environment, $\dot{c} / c=(r-\rho) / \theta$, in which the profit rate does not appear. Under these conditions, the comsumption growth rate increases regarding the interest rate and decreases regarding the subjective rate of discount, and the elasticity of intertemporal substitution. 
Equation (38) is the individual's budget constraint, and (43) is the Euler's equation. However, from the producer side we have already arrived to the next relation

$$
r=\left(\frac{\beta}{1-\beta}\right) \frac{w}{k} .
$$

By substituting (35) into equation (38), and (43), we have that

$$
\begin{aligned}
& \dot{k}=\frac{1}{1-\beta}(1+\pi) w-c-n k, \\
& \frac{\dot{c}}{c}=\frac{1}{\theta}\left((1+\pi) \frac{\beta}{1-\beta} \frac{w}{k}-\rho\right) .
\end{aligned}
$$

At steady-state conditions, with $\dot{k}=0$, the level of per capita consumption is:

$$
c=\frac{1}{1-\beta}(1+\pi) w-n k .
$$

The level of per capita capital becomes:

$$
k=(1+\pi) \frac{\beta}{\rho(1-\beta)} w .
$$

By using these results we have that consumption is a decreasing function of per capita capital. If the economy has no capital, the initial level of consumption is positive and equals $(1 / 1-\beta)(1+\pi) w$, assuming that $w>0$. This result is clearly different compared with the traditional outcome of Ramsey model, because the greater are wages or profit rate, the greater is the level of consumption, given $k=0$, whereas equation (47) corresponds to the steady-state value for per capita capital, which depends on the wage level and the profit rate, given the parameters $\rho$ and $\beta$. Under these circumstances the steady-state capital is an increasing function of profit rate and wages, and decreasing regarding the rate of time preference.

In (46) and (47) we have two features that are relevant for our analysis. Firstly, if the rate of profit is zero, we observe positive levels of per capita consumption and capital. In contrast, if we have a wage equal to zero, per capita consumption and capital vanish simultaneously, and we arrive to a trivial equilibrium.

We can now prove the existence of an economic meaningful equilibrium characterized by $k^{*}>0$, and $c^{*}>0$. To prove that $k^{*}>0$, we simply need to observe that if $w>0$ and $0<\beta<1$, we have an strictly positive level of per capita capital even if the rate of profit equals zero. To prove that $c^{*}>0$, we insert equation (47) into (46), and we arrive to the next expression:

$$
c^{*}=\frac{(1+\pi) w}{(1-\beta)}\left(1-\frac{n \beta}{\rho}\right) .
$$


By hypothesis we have that $\rho>n$, and $0<\beta<1$. If these assumptions hold, we have that $c^{*}>0$, even if we have $\pi=0$. Graphically we visualize this equilibrium as follows.

Figure 3. Steady State Equilibrium.

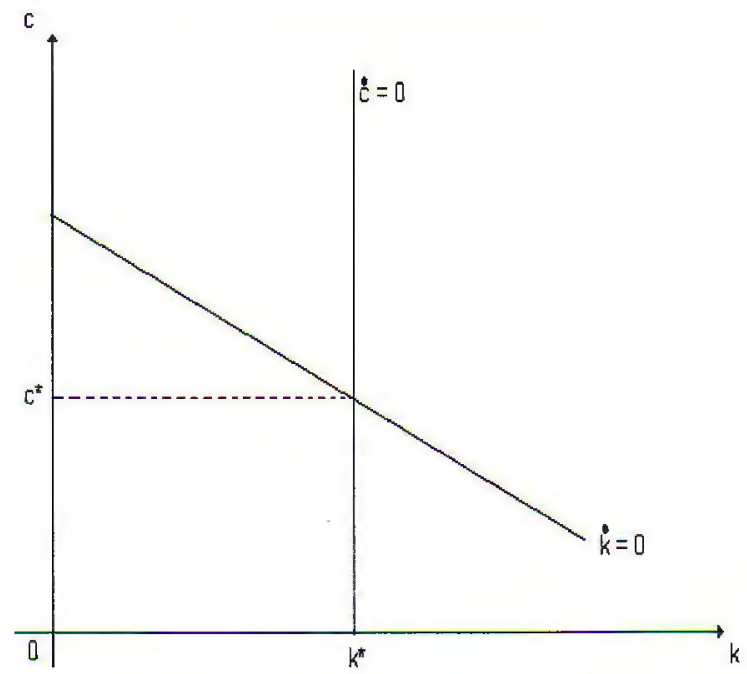

In this equilibrium we have that $c^{*}$ and $k^{*}$ both tend to increase while the profit rate and the wage increase. As a natural result it happens that if the rate of intertemporal preference is increasing, the steady state level for capital decreases. However, in the traditional Ramsey model, changes in the subjective rate of discount just modify the locus corresponding to $k^{*}$.

Following equations (47) and (48), we have that if $\rho$ is increased the steady state level of capital decreases, and the consumption level increases. The later result is not common in the traditional Ramsey model. If the parameters change, we have that the steady state equilibrium changes as well. Let us turn now to the stability conditions to observe the dynamics of the behavior out of the equilibrium, once that its existence has been demonstrated.

\subsection{Stability}

In the previous section we have proved the existence of steady state equilibrium. Now we turn to analyze the stability conditions of the model. Given that the system (44)-(45) is not linear, we will first linearize it, and then, we will obtain the eigenvalues corresponding to the characteristic matrix, in order to determine the stability conditions.

Linearizing the system (44)-(45) around the steady state, and taking into account that the steady state has been calculated in (47)-(48), we arrive to the following linear system,

$$
\dot{k}=(1+\pi) w \frac{1}{1-\beta}-c-n k,
$$




$$
\dot{c}=\rho-\frac{\rho^{2}(1-\beta)}{(1+\pi) w \beta} k .
$$

Reordering the system in matrix notation, we have

$$
\left(\begin{array}{l}
\dot{k} \\
\dot{c}
\end{array}\right)=\left(\begin{array}{cc}
-n & -1 \\
\frac{-\rho^{2}(1-\beta)}{(1+\pi) w \beta} & 0
\end{array}\right)\left(\begin{array}{l}
k \\
c
\end{array}\right)+\left(\begin{array}{c}
\frac{(1+\pi) w}{(1-\beta)} \\
\rho
\end{array}\right) .
$$

Let us denote with $\lambda_{1}$ and $\lambda_{2}$ the eigenvalues associated to the characteristic matrix

$$
\begin{aligned}
& \lambda_{1}=\frac{-n-\left(\frac{4 \rho^{2}(1-\beta)}{(1+\pi) w \beta}+n^{2}\right)^{\frac{1}{2}}}{2}, \\
& \lambda_{2}=\frac{-n+\left(\frac{4 \rho^{2}(1-\beta)}{(1+\pi) w \beta}+n^{2}\right)^{\frac{1}{2}}}{2} .
\end{aligned}
$$

Following the initial conditions assumed in this model, we have that the term

$$
\frac{4 \rho^{2}(1-\beta)}{(1+\pi) w \beta}+n^{2}>0,
$$

then we have two real roots. The root $\lambda_{1}$ is negative, and $\lambda_{2}$ is, in general, positive. Considering these results we have that the system has an stable branch.

\subsection{Unemployment}

Up to this point we have not made any distinction between labor supply and demand, and thus full employment has been automatically assumed in all results. However, starting from such a situation it will be now shown that unemployment does not exist in a steady state. For it, let $q_{d}$ be the per capita output demand obtained by adding $c$ and $n k$ from (38) under $\dot{k}=0$,

$$
q_{d}=(1+\pi)(w+r k) .
$$

Due to (35) it will be reduced to

$$
q_{d}=\left(\frac{1+\pi}{1-\beta}\right) w
$$

Now, let $e^{n t}$ be the size of labor supply at time $t$. Thus the output aggregated demand level will be given by

$$
Q_{d}=\left(\frac{1+\pi}{1-\beta}\right) w e^{n t} .
$$

Aggregated supply will be given from the production function (32), and substituting (34) in order to get the output level that would maximize the profit rate at every period.

$$
Q_{o}=\left(\frac{\alpha}{1-\alpha-\beta}\right)^{\alpha} L^{* \alpha} K^{\beta}
$$


Since the system will be in perpetual equilibrium in the product market, the following expression will be valid for every $t$,

$$
\begin{aligned}
Q_{d}-Q_{o} & =0 \\
\left(\frac{\alpha}{1-\alpha-\beta}\right)^{\alpha} L^{* \alpha} K^{\beta} & =\left(\frac{1+\pi}{1-\beta}\right) w e^{n t} .
\end{aligned}
$$

Taking into account that producers side will be specified by labor demand and capital level, we can make the following algebra,

$$
\begin{gathered}
\left(\frac{1-\beta}{1-\alpha-\beta}\right)^{\alpha} L^{* \alpha} K^{\beta}=\left(\frac{1-\alpha-\beta}{\alpha}\right)^{\alpha}\left(\frac{1-\beta}{1-\alpha-\beta}\right)^{\alpha}\left(\frac{1+\pi}{1-\beta}\right) w e^{n t}, \\
L^{\alpha} K^{\alpha}=\left(\frac{1-\beta}{\alpha}\right)^{\alpha}\left(\frac{1+\pi}{1-\beta}\right) w e^{n t} .
\end{gathered}
$$

Then, we arrive to the labor demand function,

$$
L=\alpha^{-1}(1-\beta)^{-\frac{1-\alpha}{\alpha}}((1+\pi) w)^{\frac{1}{\alpha}} e^{\frac{n t}{\alpha}} K^{-\frac{\beta}{\alpha}} .
$$

Equation (62) shows that employment level will be a function of aggregated demand of product in every $t$, depending on the population size, wages and profit rate. Moreover, it has an inverse relation with capital level. It is important to observe that employment will be positive even if profit rate becomes zero; but if $w$ becomes zero the employment level will be zero as well.

In terms of per capita capital, it may be written as follows,

$$
L=\alpha^{-1}(1-\beta)^{-\frac{1-\alpha}{\alpha}}((1+\pi) w)^{\frac{1}{\alpha}} e^{n t \frac{(1-\beta)}{\alpha}} k^{-\frac{\beta}{\alpha}} .
$$

The demonstration of unemployment existence is possible through different ways given by the model. We will take the one indicated by the labor sector's excess demand function, which is given by

$$
\begin{gathered}
L-e^{n t} \leq 0, \\
\alpha^{-1}(1-\beta)^{-\frac{1-\alpha}{\alpha}}((1+\pi) w)^{\frac{1}{\alpha}} e^{n t \frac{(1-\beta)}{\alpha}} k^{-\frac{\beta}{\alpha}}-e^{n t} \leq 0 .
\end{gathered}
$$

Although with equation (65), the existence of unemployment is possible, we have not shown so far anything about it. Substituting (47) and (63) into (64) in order to place the excess demand function in the per capita capital level of stationary state, ${ }^{7}$ we obtain the following equation

$$
e^{n t}\left(\alpha^{-1}(1-\beta)^{-\frac{1-\alpha}{\alpha}}\left(\frac{\beta}{\rho(1-\beta)}\right)^{-\frac{\beta}{\alpha}}((1+\pi) w)^{\frac{1-\beta}{\alpha}} e^{n t \frac{(1-\beta-\alpha)}{\alpha}}-1\right) \leq 0 .
$$

7 It must be considered that per capita capital is determined by consumers on the basis of an equal amount of capital granted to every new individual member born in the community, so in stationary state the amount of $k$ will be given by (47). In other words the per capita capital will be defined on labor supply, not on labor demand. 
The unemployment existence demonstration is quite simple,

$$
\lim _{w \rightarrow 0}\left(\alpha^{-1}(1-\beta)^{-\frac{1-\alpha}{\alpha}}\left(\frac{\beta}{\rho(1-\beta)}\right)^{-\frac{\beta}{\alpha}}((1+\pi) w)^{\frac{1-\beta}{\alpha}} e^{n t \frac{(1-\beta-\alpha)}{\alpha}}-1\right)<0 .
$$

Graphically, equations (64) through (66) would be shown as follows,

Figure 4. Labor Demand and Labor Supply Over Time.

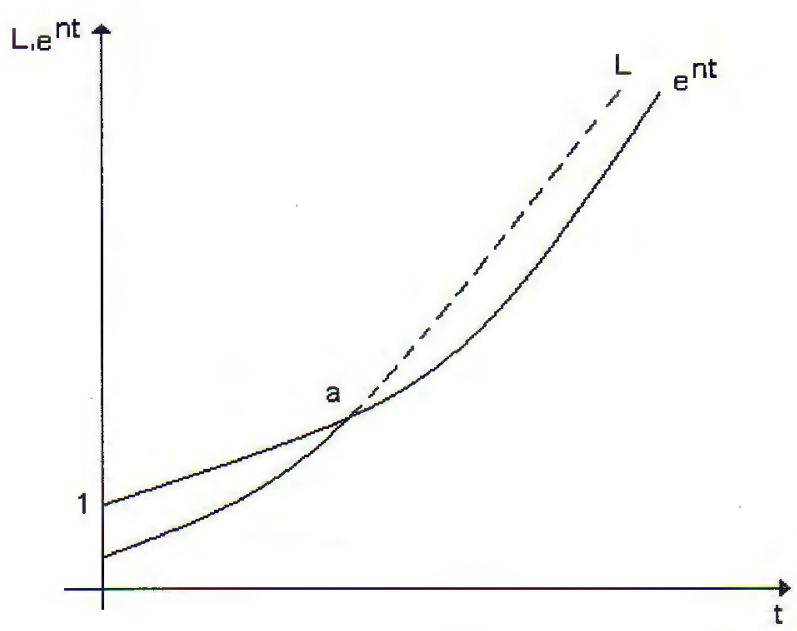

Curve $L$ represents labor demand, and curve $e^{n t}$, labor supply. The area defined between both curves, and to the left of point "a", corresponds to unemployment. It shows how from any unemployment situation, the system would evolve towards full employment represented in "a"; unless a negative wage shock displaces $L$ to the right, giving in this way a longer term to unemployment. The dashed segment of $L$, to the right of " $\mathrm{a}$ ", is referred to impossible employment levels. Thus the maximum feasible will always be determined by labor supply.

This result implies that as long as wages get lower for a null or positive profit rate, giving place to aggregated demand fluctuations, unemployment will be present in the system. This demonstration is possible due to the fact that the consumption and per capita capital are calculated regarding the size of labor supply, and can be kept constant as required in steady state, even if employment level (labor demand) fluctuates. From (46) and (47), we know that if wages change every time, steady state will change as well. It implies that any reduction in wages will generate a change in the steady state and unemployment. However, if wage reduction is an instantaneous shock, unemployment will be temporary, and its reduction toward full employment will be reached due to the demand expansion, which appears from exogenous population growth. Once the full employment is reached again, its level will be preserved until another negative shock affects the economy. 
If wage reduction is a continuous phenomena, unemployment could last through the long term. In other words, long term unemployment would take place, even more if wage reductions appear simultaneously to profit rate reductions. Then, newer steady states would replace older ones recursively.

Nill profit rate would correspond in this model to the usual long term condition of neoclassical growth models built on Solow's tradition. Under such a condition, wages reduction would be the only possible cause of unemployment, always associated to changes in steady state.

A necessary condition to keep full employment in the system is that wages are maintained equal or higher than every previous period, but never lower. The latest will, unavoidably, cause unemployment, and even though the intra generational distributive phenomena derived from unemployment has not been analyzed here, it is possible to argue along with our model, that its effects would probably imply in the future full employment situations.

\subsection{Welfare Properties of The Model}

Assume now that there is a central benevolent planner whose goal is to maximize the utility function of the representative consumer, subject to dynamic resources constraint in terms of product and with'no prices at all,

$$
\begin{gathered}
\text { Maximize } U(0)=\int_{0}^{\infty} \frac{c^{1-\theta}}{1-\theta} e^{-(\rho-n) t} \mathrm{~d} t, \\
\text { s.t. } \dot{k}=\left(1-l^{*}\right)^{\alpha} k^{\beta} L^{\alpha+\beta-1}-c-n k, \\
k(0)>0, \quad k(t) \geq 0, \quad c(t) \geq 0, \quad \forall_{t} .
\end{gathered}
$$

Here all variables are expressed in per capita terms, excepting $L$ due to the condition of decreasing returns to scale on production function. So $l^{*}$ corresponds to the per capita representation of the organizational ability inherent to the technology, and $L$ refers to total labor employment.

The definition of $\dot{k}$, as it has been made in (68), becomes from equation (31), and its per capita expression in (38). The reason of this definition is that the addition of costs multiplied by the rate of profits plus one is equal to the production function; which represents the resources constraint free of prices and of distributive variables. In this way, the equation (68) could be taken into account by the planner in order to make its maximization.

The Keynes-Ramsey condition obtained from the present value Hamiltonian for (68) is given by

$$
\frac{\dot{c}}{c}=\frac{\beta}{\theta}\left(1-l^{*}\right)^{\alpha} k^{\beta} L^{\alpha+\beta-1}-\frac{\rho}{\theta} .
$$

It means that the central planner will set the value of $l^{*}$ and $L$ in order to determine the consumption growth rate. It implies that the system will not necessarily stay in a full employment situation, since it depends on the planner's decision. It is to say that he will include employment level and technology into the economy to maximize the social welfare. 
Now, from the constraint $\dot{k}$ and the equation (69) we arrive to the following results corresponding to steady state,

$$
\begin{gathered}
c=\left(1-l^{*}\right)^{\alpha} k^{\beta} L^{\alpha+\beta-1}-n k, \\
k=\left(\frac{\rho}{\beta}\left(1-l^{*}\right)^{-\alpha} L^{-(\alpha+\beta-1)}\right)^{\frac{1}{\beta}} .
\end{gathered}
$$

These equations show that there will exist as many steady states as $\left(l^{*}, L\right)$ pairs are given by the planner. Even under full employment, the possibility of many steady states will hold unchanged. However, we could expect a Pareto optimal situation only if full employment occurs in such a system, but employment level by itself is not enuogh to ensure the maximum social welfare. Among all possible steady states there will always be one reachable state that would make (46) equal to (70), and (47) equal to (71) in the following terms

$$
(1+\pi) \frac{1}{1-\beta} w=\left(1-l^{*}\right)^{\alpha} k^{\beta} L^{\alpha+\beta-1},
$$

and

$$
(1+\pi) \frac{\beta}{\rho(1-\beta)} w=\left(\frac{\rho}{\beta}\left(1-l^{*}\right)^{-\alpha} L^{-(\alpha+\beta-1)}\right)^{\frac{1}{\beta}} .
$$

In such a case, both the decentralized economy result and that corresponding to the central planner, will agree.

\section{Conclusions}

The model developed in this paper opens several lines of research as it gives place to results that are not usual in the current literature based on dynamic framework of the Ramsey type.

The first motivation to present this contribution is to extend some results described by Noriega $(1994,2001)$ in a static environment, to a dynamic model usually and widely employed in macroeconomics: the Ramsey model, and particularly the Ramsey-Cass-Koopmans approach, which is considered as a dynamic general equilibrium analytical framework. As we have stated above, the point of departure of the problem is the maximization of the profit rate as the main target of the competitive firm.

In the first place, we have shown that the results displayed in the Ramsey framework, once we are using the profit rate maximization hypothesis, are quite different than those obtained when the producer maximizes the corresponding profits flow. The differences bear in the fact that either the wage and the rate of profit are drivers of the motion for consumption and physical capital. We arrive to a solution in which the rate of wage is, first, exogenous, and second, is determining the equations of motion for the two relevant variables of the model. The corresponding locus of steady state is formally and geometrically different if compared with the traditional results. However, the model shows properties of stability. Surely this result of stability rests on the fact that diminishing returns to capital are present in the model. 
In the second place, we conclude that the results in a decentralized economy are different than those calculated by a central planner, since the interest rate along this model is obtained in a very different way to that of the conventional Ramsey type model. 'The interest rate in this contribution does not equal the marginal product of physical capital. Thus, the result of the maximization of a utility function subject to a resources constraint becomes different than those using an individual budget constraint. Under these conditions we arrive to the fact that the central planner must choose over the level of employment; that means that the employment used in the production of final goods itself, and the number of workers employed in the firms's facilities, must be decided by the planner in order to solve the model.

In this contribution, unemployment arises as a result completely compatible with steady state general equilibrium, and gives the possibility to show that it can be a long term phenomenon. Given the fact that the rate of wage becomes an exogenous and distributive variable, and since we assume that individuals are supplying a single unit of labor on a daily basis, the full employment is just one of the possible results in a decentralized economy in which producers maximize the rate of profit. Labor market nonexistence has been continuously highlighted as a main feature of the model, a result that suggests the need of reinterpretation of the dynamics of a competitive economy.

\section{References}

Aghion, P., and P. Howitt (1998). Endogenous Growth Theory. MIT Press. Aghion, P., and J. G. Williamson (1999). Growth, Inequality and Globalization. Cambridge University Press.

Noriega, F. (1994). Teoría del Desempleo, la Distribución y la Pobreza. Editorial Ariel, México.

Noriega, F. (1998). Generalización de una Teoría Particular del Productor: Error de la Tradición Neoclásica. Investigación Económica, 58(224), pp. 185-213.

Noriega, F. (2001). Macroeconomía para el Desarrollo. Teoría de la Inexistencia del Mercado de Trabajo. McGraw-Hill Interamericana y UNAM.

Ramsey, F. (1928). A Mathematical Theory of Saving. The Economic Journal, 38.

Robinson, J. (1962). A Model of Accumulation. Essays in The Theory of Economic Growth, Macmillan.

Solow, R. (1992). La Teoría del Crecimiento, FCE, México.

Tirado, R. (1999). Crecimiento, Cambio Tecnológico, Bancos y Dinero. Tesis Doctoral, UAM.

Tirado, R. (2000). Crecimiento, Cambio Tecnológico, Bancos y Dinero: El Caso de una Economía con Firmas Innovadoras. Estudios Económicos, enero-junio.

Tirado, R. (2000a). Crecimiento, Imitación Tecnológica, Bancos y Dinero: El Caso de un País menos Desarrollado. Momento Económico, 109. 